\title{
DESAFIOS DA GESTÃO ESCOLAR NA EDUCAÇÃO INFANTIL: A CONCEPÇÃO DAS DIRETORAS
}

\author{
PRESCHOOL MANAGEMENT CHALLENGES: THE SCHOOL \\ PRINCIPALS 'CONCEPTIONS
}

\section{DESAFÍOS DE LA GESTIÓN ESCOLAR EN LA EDUCACIÓN INFANTIL: LA CONCEPCIÓN DE LOS DIRECTORES}

\author{
Nonato de Assis Miranda ${ }^{1}$ \\ mirandanonato@uol.com.br \\ Fernanda Gomes de Oliveira ${ }^{2}$ \\ fernandag.oliveira009@gmail.com \\ André dos Anjos Cangueiro Silva ${ }^{3}$ \\ andre_anjos@yahoo.com.br \\ Juncelia Marques Neves Martins de Oliveira ${ }^{4}$ \\ jmnmoliveira@gmail.com \\ Liliane Silva Costa ${ }^{5}$ \\ cskaiqueliliane@gmail.com
}

\section{RESUMO}

Este artigo apresenta os resultados de uma pesquisa que identificou e analisou as concepções de diretoras escolares acerca dos desafios da gestão da escola de educação infantil. A investigação desenvolveu-se vinculada ao Grupo de Pesquisa Gestão da Educação e Formação de Gestores: desdobramentos na qualidade do ensino vinculado à Universidade Municipal de São Caetano do Sul (USCS). Tratase de uma pesquisa de natureza qualitativa cujos dados foram obtidos por meio de entrevista com roteiro estruturado realizada com três gestoras de escolas de educação infantil (EI) do Município de Ribeirão Pires (SP). Os resultados mostram que a gestão de uma escola El não é igual a uma escola de ensino fundamental ou médio, mas diferente, pois tem desafios próprios, característicos ao público que atende (crianças de 0 a 5 anos de idade).

PALAVRAS-CHAVE: DIRETOR DE ESCOLA; EDUCAR E CUIDAR; EDUCAÇÃO PRÉ-ESCOLAR; GESTÃO ESCOLAR; RIBEIRÃO PIRES (SP)

\footnotetext{
1 Universidade Municipal de São Caetano do Sul (USCS); Universidade Paulista (UNIP).

2 Universidade Municipal de São Caetano do Sul (USCS).

3 Universidade Municipal de São Caetano do Sul (USCS); Universidade Paulista (UNIP).

4 Universidade Municipal de São Caetano do Sul (USCS).

5 Universidade Municipal de São Caetano do Sul (USCS).
} 
MIRANDA, NA; OLIVEIRA, FG; SILVA, AAC; OLIVEIRA, JMNM; COSTA, LS. Desafios da gestão escolar na educação infantil: a concepção das diretoras. Revista @mbienteeducação. São Paulo: Universidade Cidade de São Paulo, v. 13, n. 2, p. 117-135 Mai/Ago 2020.

\section{ABSTRACT}

This article presents the results of a research that identified and analyzed the school principals' conceptions about the challenges of managing the early childhood school. The research was developed in connection with the Project Education Management and Managers Training: developments in the teaching quality linked to the Municipal University of São Caetano do Sul (USCS). This is a qualitative research with data were obtained through an interview with a structured script conducted with school principals from early childhood education schools in Ribeirao Pires (SP) district. The results show that the management in the early childhood school is not the same as an elementary or high school, but different, as it has its own challenges, characteristic of the public it serves (children from 0 to 5 years old).

KEYWORDS: EDUCATE AND CARE; PRESCHOOL; SCHOOL PRINCIPAL; SCHOOL MANAGEMENT; RIBEIRÃO PIRES (SP).

\section{RESUMEN}

Este artículo presenta los resultados de una investigación que identificó y analizó las concepciones de los directores de escuela sobre los desafíos de administrar la escuela de la primera infancia. La investigación se desarrolló en relación con la Gestión de Proyectos de Educación y Capacitación de directores de escuela: desarrollos en la calidad de la enseñanza vinculados a la Universidad Municipal de São Caetano do Sul (USCS). Esta es una investigación cualitativa cuyos datos se obtuvieron a través de una entrevista con un guion estructurado realizado directores de escuelas de educación infantil en el municipio de Ribeirão Pires (SP). Los resultados muestran que la gestión de una escuela de educación infantil no es lo mismo que una escuela primaria o secundaria, sino diferente, ya que tiene sus propios desafíos, característicos del público al que sirve (niños de 0 a 5 años).

PALABRAS CLAVE: DIRECTOR DE ESCUELA; EDUCAR Y CUIDAR; EDUCACIÓN PREESCOLAR; GESTIÓN ESCOLAR; RIBEIRÃO PIRES (SP).

\section{INTRODUÇÃO}

Este artigo teve origem em estudos realizados pelo Grupo de Pesquisa Gestão da Educação e Formação de Gestores: desdobramentos na qualidade do ensino vinculado à Universidade Municipal de São Caetano do Sul (USCS). Em termos mais específicos, apresenta os resultados parciais de um projeto intitulado Organização e Gestão da Escola de Educação Infantil: desafios no cotidiano escolar que contou com 
MIRANDA, NA; OLIVEIRA, FG; SILVA, AAC; OLIVEIRA, JMNM; COSTA, LS. Desafios da gestão escolar na educação infantil: a concepção das diretoras. Revista @mbienteeducação. São Paulo: Universidade Cidade de São Paulo, v. 13, n. 2, p. 117-135 Mai/Ago 2020.

apoio financeiro do Conselho Nacional de Desenvolvimento Científico e Tecnológico $(\mathrm{CNPq})^{6}$

A gestão escolar tem a função de promover as condições e os meios de todos os recursos necessários ao bom funcionamento da escola e do trabalho em sala de aula (LIBÂNEO, 2004), cabendo aos diretores estarem à frente dessas demandas. Trata-se de uma dimensão que tem como objetivo final "[...] a aprendizagem efetiva e significativa dos alunos, de modo que, no cotidiano que vivenciam na escola, desenvolvam as competências que a sociedade demanda" (LÜCK, 2000, p. 8). Contudo, em se tratando das escolas de educação infantil (El), dadas as suas especificidades, a gestão escolar pode se constituir num desafio a mais para o diretor porque as creches e pré-escolas têm características e problemáticas específicas que envolvem desde questões históricas concernentes à sua constituição, formas de organização, até questões focais como seu público de abrangência.

Sumariamente, essas especificidades estão atreladas à questão da indissociabilidade entre o educar e o cuidar presentes na educação infantil. É importante evidenciar que nem sempre foi assim, ao contrário, isso é fruto de muitas lutas e conquistas em prol da educação nesse nível de ensino, assim como pelo reconhecimento da criança como sujeito de direitos.

A título de esclarecimentos, de alguns anos para cá, o educar e o cuidar tornaram-se indissociáveis e complementares para as crianças pequenas tendo em vista que a dicotomização entre o cuidar supostamente inerente à creche e o educar relativo à pré-escola presentes até a década de 1980, aos poucos, foi perdendo força dando lugar a uma nova concepção de educação para a infância. Até então, prevalecia uma visão "equivocada" de que nas creches desenvolvia-se um trabalho de cunho assistencialistas ao passo que na pré-escola esse trabalho tinha um caráter mais educativo. Desse modo, as atividades ligadas ao sono, à alimentação e à higiene das crianças eram menosprezadas e, portanto, diferenciadas das consideradas pedagógicas que eram consideradas sérias e de valor (CERISARA, 1999).

Em face ao exposto, surge a seguinte questão que norteou esta pesquisa: até que ponto a gestão de uma escola de educação infantil se torna mais ou menos desafiadora, considerando a especificidade da El assim como a formação inicial dos profissionais que atuam na gestão dessas escolas? Portanto, com o intuito de responder a essa indagação, buscou-se identificar e analisar as concepções de diretores acerca dos desafios da gestão da escola de educação infantil.

6 Fernanda Gomes de Oliveira contou com bolsa de Iniciação Científica (PIBIC) do CNPq para o desenvolvimento deste projeto. 
MIRANDA, NA; OLIVEIRA, FG; SILVA, AAC; OLIVEIRA, JMNM; COSTA, LS. Desafios da gestão escolar na educação infantil: a concepção das diretoras. Revista @mbienteeducação. São Paulo: Universidade Cidade de São Paulo, v. 13, n. 2, p. 117-135 Mai/Ago 2020.

\title{
JUSTIFICATIVA DO ESTUDO
}

É essencial compreender a gestão da escola de El, assim como seus desafios cotidianos se justifica, em primeiro lugar, porque é sabido que o número de pesquisas e produções científicas focalizando a gestão de instituições dessa natureza é reduzido e, por vezes, são projetos que não correspondem às especificidades das escolas de educação infantil "[...] revelando práticas que reproduzem perfis organizacionais próprios de outras etapas educacionais" (PALMEM, 2014, p. 18). Preocupada com este cenário, Kramer (2002) já vinha advertindo sobre a necessidade de se realizar estudos e pesquisas inerentes ao campo da gestão escolar e da El destacando a importância da ampliação de conhecimentos específicos para a formação dos educadores que atuam na gestão de instituições escolares de educação infantil (creches e pré-escolas), no Brasil. Não obstante, estudos recentes vêm mostrando que este quadro não mudou muito, tendo em vista que embora o número de estudos e pesquisas sobre a gestão escolar tenha aumentado:

\begin{abstract}
A primeira constatação que pode ser feita ao se examinar a literatura sobre a gestão em Educação Infantil é que as publicações são: relativamente escassas, quando comparadas à literatura sobre o mesmo tema; focalizada nas etapas posteriores da educação; baseadas, na maioria das vezes, em estudos de caso, reflexões sobre experiências localizadas com pouca abrangência; mantendo uma interlocução limitada com as discussões mais gerais que vêm acompanhando a introdução das reformas educacionais, ocorridas nas duas últimas décadas, que impactam de perto a gestão dos sistemas e unidades de ensino (FERNANDES; CAMPOS, 2015, p. 152).
\end{abstract}

Dentre outras coisas, essa escassez de estudos é explicada pelo fato de a El, especialmente a creche, ser recém-chegada ao sistema educacional. Supõe-se, portanto, que por esse motivo a gestão da escola de El, em termos mais específicos, e a educação infantil, numa perspectiva mais sistêmica, contam menos atenção no âmbito da pesquisa acadêmica quando comparadas aos níveis fundamental e médio da educação básica. É oportuno salientar ainda que os estudos focalizando a gestão da educação e da escola, em geral, têm sido realizados com o intuito de atrelar a relação entre gestão escolar e desempenho estudantil em razão da centralidade que as avaliações em larga escala ganharam, no cenário nacional, a partir da década de 1990.

Um segundo aspecto que justifica a realização desse estudo é que, em razão da inexistência de especificidade na formação de profissionais para esse nível de ensino, em geral, os gestores dessas unidades escolares desenvolvem práticas de gestão bastante similares às da escola de ensino fundamental, em especial, as que ofertam os anos iniciais desse nível de ensino (TOMÉ, 2012). Essa marca é evidenciada quando se constata, por um lado, em termos pedagógicos, práticas de 
MIRANDA, NA; OLIVEIRA, FG; SILVA, AAC; OLIVEIRA, JMNM; COSTA, LS. Desafios da gestão escolar na educação infantil: a concepção das diretoras. Revista @mbienteeducação. São Paulo: Universidade Cidade de São Paulo, v. 13, n. 2, p. 117-135 Mai/Ago 2020.

escolarização precoces e, por outro, "[...] a lógica administrativa" caracterizada "por um hibridismo de práticas democráticas e gerenciais", presentes em toda a educação básica (TOMÉ, 2012, p. 1.045).

Isso é preocupante porque "as práticas pedagógicas que compõem a proposta curricular da Educação Infantil devem ter como eixos norteadores as interações e a brincadeira" (BRASIL, 2012, p.) ao passo que as escolas de ensino fundamental têm um enfoque bem diferente, pois a ênfase desse nível de ensino é a formação básica do cidadão mediante:

\footnotetext{
I - o desenvolvimento da capacidade de aprender, tendo como meios básicos o pleno domínio da leitura, da escrita e do cálculo;

II - a compreensão do ambiente natural e social, do sistema político, da tecnologia, das artes e dos valores em que se fundamenta a sociedade;

III - o desenvolvimento da capacidade de aprendizagem, tendo em vista a aquisição de conhecimentos e habilidades e a formação de atitudes e valores;

IV - o fortalecimento dos vínculos de família, dos laços de solidariedade humana e de tolerância recíproca em que se assenta a vida social (BRASIL, 1996, p. 17).
}

Assim, o gestor da escola de El precisa ter a clareza da inseparabilidade das dimensões do educar e cuidar com o intuito de recuperar, "[...] para a função social da educação básica, a sua centralidade que é o estudante". Portanto, cuidar e educar na El, ações destinadas aos bebês, a partir de zero ano, devem ser estendidas para toda a educação básica e até mesmo o ensino superior. Logo, os profissionais das escolas de El e os gestores, de forma mais específica, precisam saber que "Cuidar e educar significa compreender que o direito à educação parte do princípio da formação da pessoa em sua essência humana" (BRASIL, 2013, p. 17).

Em razão disso, essas escolas demandam por profissionais "com a formação específica legalmente determinada" em cursos de nível médio (modalidade normal) ou superior tanto para a docência quanto para a gestão escolar. Não cabem, portanto, nas escolas de El "[...] funções de caráter meramente assistencialista, embora mantenha a obrigação de assistir às necessidades básicas de todas as crianças" (BRASIL, 2013, p. 84).

Em tese, a formação gestores escolares da educação básica incluindo, portanto, a que ocorre nas escolas de El, é realizada principalmente, mas não exclusivamente, nos cursos de Pedagogia, especialmente no Estado de São Paulo. Não obstante, em razão das orientações curriculares desse curso (BRASIL, 2006) que dão ênfase à formação docente em detrimento da gestão e organização escolar (MIRANDA; VERASZTO, 2014), a possibilidade de os egressos desse curso não desenvolverem, satisfatoriamente, habilidades e competências de gestão com foco nas especificidades das escolas de El é grande. 
As supostas fragilidades presentes na formação inicial do gestor da escola de El podem representar um desafio tanto para o profissional quanto para o sistema de ensino no qual a escola esteja inserida. Por conta disso, muitas redes de ensino estaduais e municipais tomam para si a responsabilidade para a formação continuada de gestores pelo entendimento de que esses profissionais desempenham uma função importante no âmbito das escolas e para tal devem estar bem qualificados.

\section{ASPECTOS HISTÓRICOS DA EDUCAÇÃO INFANTIL}

Para compreender a gestão da escola de El é necessário fazer alguns apontamentos sobre alguns aspectos históricos inerentes a esse nível de ensino. Isso se faz necessário porque o tratamento dado às crianças de zero a cinco anos de idade, na contemporaneidade, representa um grande avanço, mas, historicamente, nem sempre, as crianças foram consideradas socialmente. Para contextualizar esse avanço, Frabboni (1998) sugere três fases distintas. São elas: a infância negada, a infância industrializada e a infância de direitos.

$\mathrm{Na}$ infância negada (até o século $\mathrm{XV}$ ), as crianças eram consideradas como miniadultos, conforme pode ser constado, por exemplo, em obras de arte da época. Nesse período, desconhecia-se a infância; muitas crianças morriam cedo e, por esse motivo, os pais não criavam laços afetivos com elas. Caso conseguissem chegar aos sete anos de idade, eram preparadas para o trabalho e inseridas no mundo adulto. As escolas dessa época estavam vinculadas às igrejas e não se pensava em um currículo voltado para a educação da infância.

Na segunda fase (infância industrializada que se estende do século XVI ao século XVII), padres, educadores e moralistas começam a perceber a fragilidade das crianças e, gradualmente, começam a se preocupar mais com seu bem-estar e instrução, assim como a criticar os costumes da época. Nesse período, surgem as primeiras escolas com o intuito de ensinar, mas também de reduzir o número de crianças no mundo adulto (ANDRADE, 2010). Apesar dessa mudança de concepção sobre a infância, as famílias eram as mesmas, portanto, não eram novas, mas "[...] o sentimento de família que surge nos séculos XVI e XVII, inseparável do sentimento de infância" (KRAMER, 1987, p. 18), representou uma novidade para a época.

Apesar desse novo sentimento de família identificado nesse período, o que se constata é que, somente a partir do século XVIII, que ocorrem mudanças consideradas significativas sobre a educação da infância. Essa mudança de paradigma está atrelada ao surgimento da família moderna, ao crescente interesse pela leitura que reforçava a estratificação social da época, pois nesse período as pessoas eram subdivididas entre as sabiam ou não ler. Assim, os mais velhos, possuidores de maior inteligência e 
MIRANDA, NA; OLIVEIRA, FG; SILVA, AAC; OLIVEIRA, JMNM; COSTA, LS. Desafios da gestão escolar na educação infantil: a concepção das diretoras. Revista @mbienteeducação. São Paulo: Universidade Cidade de São Paulo, v. 13, n. 2, p. 117-135 Mai/Ago 2020.

conhecimento, começaram a entender a importância de estudar. Esse comportamento acabou culminando no aumento da procura por escolas e, consequentemente, de crianças estudando. Contudo, esse cenário era para as famílias mais abastadas e não para todos (KRAMER, 1987; GOMES, 2015).

Por fim, temos a terceira fase intitulada de a infância de direitos ou criança sujeito social, quando a concepção de proteção às crianças emerge com o surgimento da Psicologia, da Pedagogia e da Psicanálise (ANDRADE, 2010). Com base nos estudos realizados nessas áreas de conhecimento, começamos a entender mais sobre o ser humano com destaque para o entendimento de como se dá o seu desenvolvimento. Assim, surge o entendimento de que o desenvolvimento humano está atrelado, dentre outras coisas, aos traumas, aos problemas de vício em adultos, aos problemas de saúde e a depressão, por exemplo (FRABONI, 1998).

Em razão disso, mas não somente, os castigos e punições físicas foram proibidos, tendo em vista que surgiram das instituições como o Fundo Internacional de Emergência para a Infância das Nações Unidas (UNICEF) que é um órgão das Nações Unidas que tem o objetivo de promover a defesa dos direitos das crianças, assim como ajudar a dar resposta às suas necessidades e contribuir para o seu desenvolvimento.

No Brasil, o direito ao atendimento, assim como à educação das crianças de zero a cinco anos de idade, está resguardado na Constituição Federal de 1988 que atribui ao Estado o dever em relação à educação, oferecida em regime de colaboração pelos sistemas de ensino da União, dos Estados, do Distrito Federal e dos Municípios (BRASIL, 2013). A incorporação das creches e pré-escolas no capítulo da educação na Constituição Federal de 1988 (art. 208, inciso IV) impacta todas as outras responsabilidades do Estado em relação à educação infantil. A partir de então, o direito das crianças de zero a cinco anos de idade à matrícula em escola pública (art. 205), gratuita e de qualidade (art. 206, incisos IV e VI), igualdade de condições em relação às demais crianças para acesso, permanência e o pleno aproveitamento das oportunidades de aprendizagem propiciadas (art. 206, inciso I), fica regulamenta (BRASIL, 1988; BRASIL, 2013).

Outro marco regulatório importante acerca do direitos da criança é o Estatuto da Criança e do Adolescente (ECA) que se constitui em um conjunto de normas jurídicas que tem como objetivo a proteção integral da criança e do adolescente aplicando medidas, quando necessário, e expedindo encaminhamentos para o juizado de menores, em casos de maus tratos, abuso de poder, abuso sexual etc. (BRASIL, 2010). No caso específico da educação, o ECA tem papel preponderante na garantia desses direitos da criança, cabendo aos gestores das escolas de educação infantil atenção ao contido nesse dispositivo legal atentando-se para o fato de que 
"[...] a educação infantil, primeira etapa da educação básica, tem como finalidade o desenvolvimento integral da criança até cinco anos de idade, em seus aspectos físico, psicológico, intelectual e social, completando a ação da família e da comunidade" (BRASIL, 1996, p. 17).

Assim, a gestão da escola de El deve estar atrelada às concepções de infância e de criança "[...] tomando-as, assim, sujeitos que aprendem por meio das relações que estabelecem com objetos e pessoas" (LUZ; MELLO, 2015, p. 117). Feito isso, a possibilidade de as escolas de El tornarem-se espaços de compartilhamento de significados, de aprendizagens mediatizadas pela reflexão conjunta sobre planos de trabalho, problemas e soluções relacionados à aprendizagem dos alunos e ao funcionamento da instituição é bem maior. (LIBÂNEO; OLIVEIRA; TOSCHI, 2012).

Por fim, cabe mencionar que a relevância social desse projeto de pesquisa está centrada nas possíveis contribuições que poderá oferecer para a reflexão acerca das práticas de gestão identificadas nas escolas de educação infantil.

\section{MÉTODO}

Considerando-se os objetivos e as características dessa pesquisa, optouse pela abordagem qualitativa de pesquisa, por entender que se trata de "[...] uma designação que abriga correntes de pesquisa muito diferentes" (CHIZZOTTI, 2003, p. 78), na medida em que essas correntes "[...] se fundamentam em alguns pressupostos contrários ao modelo experimental" (CHIZZOTTI, 2003, p. 78), que não são utilizados nesta pesquisa. Ademais,

Na pesquisa qualitativa, o cientista é ao mesmo tempo o sujeito e o objeto de suas pesquisas. O desenvolvimento da pesquisa é imprevisível. $O$ conhecimento do pesquisador é parcial e limitado. O objetivo da amostra é de produzir informações aprofundadas e ilustrativas: seja ela pequena ou grande, o que importa é que ela seja capaz de produzir novas informações (DESLAURIERS, 1991, p. 58).

\section{CONTEXTO DA PESQUISA}

Ribeirão Pires está localizado no Grande ABC Paulista, que congrega sete municípios (Santo André, São Bernardo do Campo, São Caetano do Sul, Diadema, Mauá, Ribeirão Pires e Rio Grande da Serra), sendo considerado um dos municípios menos favorecidos, economicamente, dessa região com PIB per capita de $\mathrm{R} \$ 25.002,279$ (IBGE, 2017).

Com relação à educação, Ribeirão Pires (SP) contava em 2010 com uma taxa de escolarização de $97,4 \%$ muito próxima da média nacional de 2015 que foi de 
MIRANDA, NA; OLIVEIRA, FG; SILVA, AAC; OLIVEIRA, JMNM; COSTA, LS. Desafios da gestão escolar na educação infantil: a concepção das diretoras. Revista @mbienteeducação. São Paulo: Universidade Cidade de São Paulo, v. 13, n. 2, p. 117-135 Mai/Ago 2020.

$98,6 \%$. Outro dado importante é que esse município vem apresentando indicadores considerados altos no desempenho das avaliações nacionais alcançando, em 2017, 7,0 pontos (escala de escala de 0 a 10) no Índice de Desenvolvimento da Educação Básica (IDEB) - ensino fundamental (anos iniciais) e 5,4 nos anos finais $\left(6^{\circ}\right.$ ao $9^{\circ}$ anos) desse mesmo nível de ensino (IBGE, 2017).

Com relação ao cenário da educação infantil, Ribeirão Pires contabilizou, em 2018, 5.028 matrículas ( 0 a 5 anos de idade); desse quantitativo 2.388 eram da creche e 2.640 da pré-escola (BRASIL, 2019). Para atender a esse público de crianças, o município contava (2018) com 45 escolas de educação infantil, 788 professores sendo 633 nas creches 171 nas pré-escolas (IBGE, 2018).

É oportuno salientar que Ribeirão Pires (SP) vem apresentando dificuldade para atender as metas educacionais de acesso à educação infantil há alguns anos. Em 2010 (último ano da vigência do Plano Nacional de Educação), por exemplo, apesar de o município ter um quantitativo de $83,6 \%$ das crianças em idade pré-escolar, apenas $29,3 \%$ das crianças com idades entre 0 e 3 anos estavam matriculadas em creches (MIRANDA; APARÍCIO; ANDRADE, 2015).

\section{COLETA DE DADOS}

Para tentar compreender a atuação de gestoras frente às demandas cotidianas atuais foram escolhidas três escolas de El da Rede Municipal de Educação de Ribeirão Pires (SP) no Grande ABC Paulista. A primeira escola está situada no Bairro Bertoldo e funciona nos turnos matutino e vespertino atendendo cerca de 170 alunos que vão do berçário ao maternal. A segunda escola está situada no bairro Jardim Santa Luzia, uma pré-escola que atende em torno de 150 alunos, também nos períodos de manhã e tarde. Já a terceira escola está situada no Bairro Jardim Itacolomi, bem próxima ao centro da cidade cujo número de alunos é de 270 alunos de $\mathrm{El}$, com salas de berçário e maternal' .

Para conhecer as concepções das gestoras acerca dos desafios da gestão da escola de El foi realizada uma entrevista com as gestoras de duas creches e uma pré-escola do município de Ribeirão Pires (SP), no Grande ABC Paulista. Optou-se pela entrevista pelo entendimento que essa técnica de coleta de dados atendia os objetivos da pesquisa, pois consiste num encontro entre duas pessoas:

[...] a fim de que uma delas obtenha informações a respeito de determinado assunto, mediante uma conversação de natureza profissional. É um procedimento utilizado na investigação social, para a coleta de dados

7 Esse número de matricula refere-se ao ano de 2018, conforme informações obtidas no https://www.qedu.org. br/. Acesso em: 20 abr. 2020. 
ou para ajudar no diagnóstico ou no tratamento de um problema social (MARCONI; LAKATOS, 1999, p. 94).

Ainda segundo essas autoras, há diferentes tipos de entrevistas, que variam de acordo com o propósito do entrevistador: padronizada ou estruturada, despadronizada ou não estruturada e o painel. Neste estudo optou-se pelo tipo padronizado tendo vista que foi elaborado um roteiro para orientar a entrevista utilizando-se como ponto de partida a questão norteadora e os objetivos da pesquisa. Contudo, tomou-se o devido cuidado para que o roteiro não se transformasse numa "camisa de força" e impedisse as diretoras de falar. Ao contrário, elas puderam falar à vontade sobre os desafios da gestão escolar na educação infantil, apenas tomou-se cuidado para que elas não desviassem do assunto.

Foram realizadas três entrevistas, no mês de novembro de 2019 , cuja duração girou em torno de 20 minutos cada uma. Com relação ao local, optou-se pelas escolas onde as participantes atuam, mesmo ciente que poderia haver interrupções em razão das demandas inerentes ao cotidiano escolar. Antes de iniciar a entrevistas, agendadas previamente, foram explicitados os objetivos da pesquisa, assim como garantido às participantes o anonimato delas, o que as deixou mais seguras para expressarem suas concepções sobre o assunto investigado. Assim, as gestoras serão nomeadas como G (gestora) e terão um número para diferenciá-las.

É oportuno salientar que durante as entrevistas das gestoras 1 e 3, não houve interrupções, pois elas solicitaram às funcionárias da Secretaria que não as interrompessem naquele momento. Contudo, com relação à segunda escola, o telefone tocou muitas vezes e como nenhum funcionário da escola o atendia, a diretora pediu para interromper a entrevista e atender ao telefone que era um pai de aluno (o assunto não foi informado). Essa conversa com o pai durou cerca de 10 minutos sendo que, assim que desligou o telefone, a diretora pediu para continuar a entrevista. É oportuno salientar que essa interrupção não prejudicou a entrevista, mas serviu para compreender a complexidade do cotidiano de uma escola, seja ela de educação infantil ou não. Com base nessa situação e das outras duas escolas investigadas, depreende-se que:

[...] um diretor de escola é um gestor da dinâmica social, um mobilizador e orquestrador de atores, um articulador da diversidade para dar-lhe unidade e consistência, na construção do ambiente educacional e promoção segura da formação de seus alunos (LÜCK, 2000, p. 16).

Para dar conta dessa empreitada, o diretor carece de formação que se funda no desenvolvimento de conhecimentos e habilidades que o qualificam para o exercício da profissão. Não obstante, é sabido que a formação inicial do gestor, que atua no Estado de São Paulo, fica a cargo do curso de Pedagogia, que não tem sido 
suficiente para qualificá-lo a lidar com os desafios da gestão escolar, pois tem ênfase na formação docente (MIRANDA; VERASZTO, 2014).

Com relação à formação inicial, as três participantes são pedagogas, mas frequentaram outros cursos de graduação e especialização. Além disso, são bastante experientes: a G1 tem 19 anos de docência, 5 como gestora e 7 como coordenadora pedagógica. A G2 tem 9 anos de docência, mas apenas um ano de gestão. Por fim, a G3 conta com 26 anos de experiência na gestão, mas estranhamente apenas 2 de docência.

\title{
CONCEPÇÕES DOS DIRETORES SOBRE OS DESAFIOS DA GESTÃO DA ESCOĽA DE EDUCAÇÃO INFANTIL
}

A gestão da escola não é uma atividade neutra tendo em vista é uma ação desenvolvida em um espaço comunitário envolvendo professores, funcionários, alunos e pais (LIBÂNEO, 2004). A gestão, assim como a organização, são temas centrais das políticas educacionais, na contemporaneidade em todo o mundo, mas

\begin{abstract}
[...] em diferentes contextos e momentos históricos, o debate sobre a organização das escolas e sobre a relação destas com a comunidade em que estão situadas [...] implica diferentes concepções sobre a organização do espaço público e as responsabilidades do Estado, da sociedade e dos profissionais da educação (MEDEIROS; LUCE, 2006, p. 15).
\end{abstract}

No Brasil, a situação não é diferente sendo que o debate sobre a gestão escolar toma vulto a partir de 1970 em razão da luta da classe trabalhadora pelo direito de vaga de seus filhos nas escolas públicos. A década seguinte é marcada pela organização sindical dos professores e a conquista de planos de carreira com valorização da formação (MEDEIROS; LUCE, 2006).

Nesse contexto, se por um lado, é no bojo dessa luta que surge a noção de gestão democrática, por outro, é a partir desse momento que o trabalho do diretor de escola torna-se mais desafiador. Dentre outras coisas, isso acontece porque a visão que se tinha de administração escolar não cabia mais nesse novo contexto. A partir de então, o termo gestão escolar surge com o intuito de superar o enfoque limitado da administração escolar considerando-se que os problemas educacionais são complexos e, por esse motivo demandam uma visão global e abrangente, assim como uma ação articulada, dinâmica e participativa (LÜCK, 2006).

Pensando nisso, fizemos a seguinte indagação às diretoras participantes desta pesquisa: em geral, acredita-se que a escola de El tem menos conflitos do que as escolas que ofertam o ensino fundamental (EF) e o ensino médio (EM) e, por 
MIRANDA, NA; OLIVEIRA, FG; SILVA, AAC; OLIVEIRA, JMNM; COSTA, LS. Desafios da gestão escolar na educação infantil: a concepção das diretoras. Revista @mbienteeducação. São Paulo: Universidade Cidade de São Paulo, v. 13, n. 2, p. 117-135 Mai/Ago 2020.

esse motivo a gestão pode ser menos desafiadora. Qual sua concepção sobre esse assunto?

Antes mesmo de apresentar e analisar os depoimentos dos participantes da pesquisa é importante salientar que o bom funcionamento de uma escola ocorre quando são colocadas em ação as funções de planejar, organizar, dirigir e avaliar. Assim, quando o diretor conduz essas funções mediante várias ações e procedimentos ele está fazendo a gestão da escola (LIBÂNEO, OLIVEIRA, TOSCHI, 2012).

Com relação ao grau de complexidade da gestão escolar é sabido que vários fatores podem intervir nesse processo, mas essa complexidade ganha força quando ocorre a ampliação da ação do gestor (ALBUQUERQUE, 2014). Nessa perspectiva, não importa se a escola é de El, ensino fundamental ou ensino médio, a complexidade da gestão não muda muito, pois o diferencial está na ampliação ou não da ação gestora, assim como a especificidade de cada nível de ensino.

A despeito da suposição de que a gestão da escola de El possa ser menos desafiadora em razão do público que frequenta essa escola, a pesquisa mostra um cenário diferente. O que se verificou é que essa é uma visão reducionista da gestão da escola de El. Sobre este assunto, uma gestora asseverou: "os desafios são os mesmos" comparando uma escola de El com as de EF ou EM, pois entende que "as crianças podem não ser questionadoras[nas escolas de El], mas os pais o são" aliás, acrescentou a diretora, "eles são mais questionadores do que os pais do fundamental, por incrível que pareça" (G1). Portanto, se por um lado, no EF "existe a preocupação com o aprendizado e o relacionamento", por outro, na El "a gente se preocupa com a socialização deles, a gente tem que se preocupar com o aprendizado né?" (G1).

Nota-se, portanto, essa gestora compreende que a gestão da escola de El é tão desafiadora quanto as escolas de EF e EM. Assim, se por um lado, as escolas de El não têm alunos supostamente mais críticos, por outro, os pais são mais presentes, questionadores, atentos com a vida escolar do filho. Ademais, as escolas de El têm outras demandas como, por exemplo, a compreensão da indissociabilidade entre o ato de educar e cuidar no processo educativo (BRASIL, 2017).

Por sua vez, a segunda participante tem uma visão diferente sobre o assunto. Para ela, "As crianças questionam sim [...], pois, [...] hoje as crianças já não aceitam o não [...] elas querem saber o porquê" do não (G2). Assim, se em um passado não muito distante isso era perturbador, atualmente, esse tipo de atitude da criança é bem visto e está presente na Base Nacional Comum Curricular (BNCC) que garante a elas o direito de "Expressar, como sujeito dialógico, criativo e sensível, suas necessidades, emoções, sentimentos, dúvidas, hipóteses, descobertas, opiniões, questionamentos, por meio de diferentes linguagens" (BRASIL, 2017, p. 38). Embora essa gestora não tenha sido indagada se sua prática estava pautada nas orientações da BNCC, infere- 
MIRANDA, NA; OLIVEIRA, FG; SILVA, AAC; OLIVEIRA, JMNM; COSTA, LS. Desafios da gestão escolar na educação infantil: a concepção das diretoras. Revista @mbienteeducação. São Paulo: Universidade Cidade de São Paulo, v. 13, n. 2, p. 117-135 Mai/Ago 2020.

se que sim. É oportuno sinalizar que, a Secretaria Municipal de Ribeirão Pires (SP) fez um amplo debate com sua rede sobre a BNCC e, talvez, por esse motivo ela tenha feito o seguinte depoimento: "Eu sempre incentivo a equipe de professores a explicar tudo para as crianças". Ademais, ela sinalizou que encoraja seus professores a "[...] questionar as crianças" (G2) com vistas a formar sujeitos críticos tal como o preconizado nesse e em outros documentos que normatizam a El.

Para além dessa concepção de desenvolvimento infantil, outra gestora sinaliza que o cotidiano da escola é marcado por muitos desafios. Na concepção dela isso acontece:

Porque na escola a gente não lida só com a criança, a gente lida com uma comunidade né? $\mathrm{E}$ a nossa, por ser de crianças pequenas eu acho que a nossa preocupação é muito maior, por exemplo, aqui é uma creche que a gente abre às 7 horas da manhã e fecha às 7 horas da noite, então as crianças passam a maior parte do tempo com a gente (G3).

É sabido que a gestão escolar se insere num:

[...] conjunto de normas, diretrizes, estrutura organizacional, ações e procedimentos que asseguram a racionalidade do uso dos recursos humanos, materiais, financeiros e intelectuais como a coordenação e o acompanhamento do trabalho das pessoas (LIBÂNEO, OLIVEIRA, TOSCHI, 2012, p. 411).

Mas, na escola de $\mathrm{El}$, a gestão é mais do que isso, ela tem um caráter diferenciado e, portanto, mais complexo, porque lida com crianças que têm direito de aprendizagem e de desenvolvimento assegurado em diversos documentos legais, tais como: o ECA (BRASIL, 1990), a Lei de Diretrizes e Bases (BRASIL, 1996), as Diretrizes Curriculares Nacionais da Educação Infantil (BRASIL, 2009) e, mais recentemente, a BNCC (BRASIL, 2017).

Isso não quer dizer que os adolescentes não tenham esses mesmos direitos, mas as crianças de 0 a 5 anos têm necessidades bem especificas merecendo, portanto, atenção diferenciada, pois nas escolas de El "[..] tem os bebezinhos que são de três meses até um ano e pouquinho. Na verdade, são todos bebês" (G3). Assim, os desafios são muitos, pois o gestor tem de lidar com diferentes demandas que ultrapassam o limite da organização e gestão. Por exemplo, quando "[...] as professoras, chegam e falam 'aí fulano mordeu', a problemática com criança é de relacionamento; de disputa por brinquedos, por espaço, por atenção né?" (G3). Esse depoimento denota o cotidiano das escolas de El é complexo sendo que quanto menores forem as crianças, maior será esse desafio, pois:

Um dos grandes desafios para os educadores que trabalham na educação infantil é o trabalho com bebês. O desafio existe porque, ao se trabalhar com crianças maiores, diversas dinâmicas permitem que se desenvolva 
uma relação destas com o educador e com a aprendizagem. Já com bebês, é necessário que o trabalho seja desenvolvido a partir da base, ou seja, desde as primeiras atividades que vão estimulá-los na tarefa de descobrir o mundo e o meio que os cerca (TREZZI; ROSA, 2020, p. 179).

Mas os problemas não se restringem ao ambiente escolar tendo em vista que "[...] às vezes a criança vem de casa com algum problema afetivo, de insegurança [...]" (G3) e a gestão tem de encontrar uma solução. Outra situação bastante comum nas escolas de El é vinda de crianças para escola doente. A gestora da escola 3 considera que, talvez, esse seja um dos problemas mais sérios que ela tem de lidar no cotidiano escolar e desabafa: "[...] quando a criança tá gripada, tá doente e os pais não aceitam. Eles não querem vir buscar [ a criança] para levar [a criança] no médico" (G3). É sabido que "Os aspectos relativos à educação infantil como saúde, afeto, segurança, alimentação, interação, estimulação, brincadeira, entre outros, devem integrar o cuidar/educar de forma dinâmica" (TREZZI; ROSA, 2020, p. 179), mas se a criança está doente, o cenário é outro, faz-se necessário buscar ajuda médica e a gestão da escola não pode assumir essa responsabilidade sozinha.

É oportuno salientar que a despeito dos desafios aqui externalizados pelos gestores, esse cenário não pode ser interpretado de forma simplista, como, por exemplo, qualificando essas famílias como descompromissadas com a educação escolar do filho. É necessário relativizar essa situação porque a realidade socioeconômica de muitas famílias não lhes permite atender a gestão da escola a todo o momento que são chamadas. Em geral, os pais saem para trabalhar cedo retornando somente no final do dia quando têm condições de buscar seus filhos na escola, com destaque para as de natureza pública. Portanto, essa é uma situação bastante delicada que requer compreensão e parceria por parte das instituições escolar e familiar.

Em face ao exposto, uma das participantes tentou descrever uma situação que envolveu busca de solução, bom senso e proatividade em sua prática de gestão no cotidiano escolar. Ou seja, quando uma mãe é chamada pela direção e tem de deixar o emprego para buscar seu filho na creche no horário de trabalho, em geral, na concepção da gestora, ela "[...] acha que vai perder o emprego". Ciente dessa preocupação, a gestora tenta minimizar a angústia da mãe afirmando que "não", que ela não perderá o emprego tecendo o seguinte comentário: "[...] tem uma lei que te ampara, você tem que vir pegar a criança" (G3). Supostamente preocupada com a interpretação de sua resposta, a gestora enfatiza que ao tomar essa atitude para com a mãe, a escola [a diretora] não está se negando a cuidar da criança, mas considera que "[...] ficar com a criança em estado de sofrimento, [...] não pode" (G3).

Depreende-se, portanto, que nessa prática profissional, está implícita a concepção de que a criança é um: 
[...] sujeito histórico e de direitos, que, nas interações, relações e práticas cotidianas que vivencia, constrói sua identidade pessoal e coletiva, brinca, imagina, fantasia, deseja, aprende, observa, experimenta, narra, questiona e constrói sentidos sobre a natureza e a sociedade, produzindo cultura (BRASIL, 2009, p.).

Ademais, trata-se de uma prática de gestão a partir da qual não "[...] prevalece uma visão mais burocrática e tecnicista da escola" e sim uma postura orientada na perspectiva da concepção sociocrítica que vê a organização escolar como um sistema que agrega pessoas, reconhece a intencionalidade de suas ações, a importância das interações sociais e as relações da escola com sua comunidade (LIBÂNEO; OLIVEIRA; TOSCHI, 2004).

\section{CONSIDERAÇÕES FINAIS}

A gestão da escola, assim como a organização, correspondem à necessidade de a instituição escolar dispor das condições e dos meios para a realização de seus objetivos específicos (LIBÂNEO, OLIVEIRA, TOSCHI, 2012). Dar conta dessa empreita não é uma tarefa fácil para o gestor independentemente de a escola ser de El ou de qualquer outro nível de ensino.

É importante que se compreenda que a El, como primeira etapa da educação básica, é o início e o fundamento do processo educacional merecendo, portanto, atenção especial. "A entrada na creche ou na pré-escola significa, na maioria das vezes, a primeira separação das crianças dos seus vínculos afetivos familiares para se incorporarem a uma situação de socialização estruturada" (BRASIL, 2017, p. 36) o que representará, tanto para a gestão como para o conjunto de educadores, um grande desafio dada a especificidade das crianças nessa faixa etária, conforme constatado nos depoimentos das participantes desta pesquisa.

Assim, os resultados deste estudo mostram que a gestão da escola de EI difere um pouco da que ocorre nos outros níveis de ensino porque as escolas de $\mathrm{El}$ são espaços que cuidam e educam crianças de 0 a 5 anos de idade. Além disso, em razão das especificidades desse público, a gestão dessas escolas é caracterizada por demandas diversas que não, necessariamente, sejam as mesmas das escolas de EF e EM, mas nem por isso mais simples ou menos desafiadora.

Em face ao exposto, não dá para afirmar se a gestão das escolas de El é mais ou menos desafiadora quando comparada às escolas EF e EM, mas é possível asseverar que é diferente e tem especificidades próprias em razão de suas caraterísticas e das novas demandas acerca dos direitos assegurados às crianças de 0 a 5 anos de idade, nos últimos anos, especialmente, com o que se espera do currículo, conforme o preconizado na BNCC (BRASIL, 2017). 
MIRANDA, NA; OLIVEIRA, FG; SILVA, AAC; OLIVEIRA, JMNM; COSTA, LS. Desafios da gestão escolar na educação infantil: a concepção das diretoras. Revista @mbienteeducação. São Paulo: Universidade Cidade de São Paulo, v. 13, n. 2, p. 117-135 Mai/Ago 2020.

\section{REFERÊNCIAS}

ALBUQUERQUE, Helena Machado de Paula. Gestor escolar: dimensões de sua ação. Revista@mbienteeducação, Universidade Cidade de São Paulo, v. 7, n. 1, p. 179-187, jan./abr. 2014.

ANDRADE, Lucimary Bernabé Pedrosa de. Educação Infantil: discurso, legislação e práticas institucionais. São Paulo: Cultura Acadêmica, 2010.

BARDIN, Laurence. Análise de conteúdo. Lisboa: Edições 70, 1991.

BRASIL. Constituição da República Federativa do Brasil. Brasília: Senado Federal, 1988.

BRASIL. Lei no 9.394. Lei de Diretrizes e Bases da Educação, de 20 de dezembro de 1996. Estabelece as diretrizes e bases da educação nacional. Diário Oficial da União. Brasília, 20 dez. 1996.

BRASIL. Resolução n 5, de 17 de dezembro de 2009. Fixa as Diretrizes Curriculares Nacionais para a Educação Infantil. Brasília: CNE/CEB, 2009.

BRASIL. Diretrizes Curriculares Nacionais da Educação Básica. Ministério da Educação. Secretaria de Educação Básica. Diretoria de Currículos e Educação Integral. Brasília: MEC, SEB, DICEI, 2013.

BRASIL. Diretrizes curriculares nacionais para a educação infantil. Secretaria de Educação Básica - Brasília: MEC, SEB, 2010.

BRASIL. Estatuto da criança e do adolescente: lei n. 8.069, de 13 de julho de 1990, e legislação correlata [recurso eletrônico]. - 9. ed. - Brasília: Câmara dos Deputados, Edições Câmara, 2010.

BRASIL. Base nacional comum curricular. Brasília: CNE, 2017.

BRASIL. Instituto Nacional de Estudos e Pesquisas Educacionais Anísio Teixeira. Sinopse Estatística da Educação Básica 2018. Brasília: Inep, 2019. Disponível em: http://portal.inep.gov.br/sinopses-estatisticas-da-educacao-basica. Acesso em: 20 abr. 2020.

CERISARA, Ana Beatriz. Educar e cuidar: por onde anda a educação infantil? Perspectiva, Florianópolis, v. 17, n. especial, p. 11-24, jul./dez. 1999.

CHIZZOTTI, Antônio. Pesquisa em ciências humanas e sociais. 6. ed. São Paulo: Cortez, 2003. 
DESLAURIERS, Jean-Pierre. A pesquisa qualitativa: guia prático. Montreal: McGraw-Hill, 1991.

FERNANDES, Fabiana Silva; CAMPOS, Maria Malta. Gestão da educação infantil: um balanço de literatura. Educ. rev., Belo Horizonte, v. 31, n. 1, p. 139-167, mar. 2015.

FRABBONI, Franco. A escola infantil entre a cultura da infância e a ciência pedagógica e didática. In: ZABALZA, M. Qualidade em educação infantil. Porto Alegre: Artmed, 1998. cap. 4, p. 63-92.

GOMES, Débora. História da criança: breves considerações sobre concepções e escolarização da infância. Anais do XII Encontro Nacional de Educação EDUCERE. PUCPR, 26 a 29/10/2015.

IBGE - INSTITUTO BRASILEIRO DE GEOGRAFIA E ESTATÍSTICA, 2000. Censo escolar: sinopse 2018. Disponível em: https://cidades.ibge.gov.br/brasil/sp/ribeiraopires/pesquisa/13/78117. Acesso em: 20 abr. 2020.

KRAMER, Sonia. A política do pré-escolar no Brasil: a arte do disfarce. Rio de Janeiro: Dois Pontos, 1987.

KRAMER, Sonia. Formação de profissionais de educação infantil: questões e tensões. In: MACHADO, M. L. (Org) Encontros e Desencontros em Educação Infantil. São Paulo: Cortez, 2002 p.117-132.

LIBÂNEO, José Carlos. Organização e gestão escolar: teoria e prática. 5. ed. Goiânia: Alternativa, 2004.

LIBÂNEO, José Carlos; OLIVEIA, João Ferreira de; TOSCHI, Mirza Seabra. Educação escolar: política e organização: 10. ed. São Paulo: Cortez, 2012.

LÜCK, Heloísa. Perspectivas da gestão escolar e implicações quanto à formação de seus gestores. In. Gestão escolar e formação de gestores. Em Aberto, Brasília, v. 17, n. 72 , p. 1-195, fev./jun. 2000. 72.

LÜCK, Heloisa. Dimensões de gestão escolar e suas competências. Curitiba: Editora Positivo, 2009.

LÜCK, Heloisa. Concepções e processos democráticos de gestão educacional. Petrópolis: vozes, 2006.

LUZ, Anízia Aparecida Nunes; MELLO, Lucrécia Stringhetta. Gestão na educação infantil: concepções e práticas no espaço de formação. Anais do XII Educere, Curitiba-PR, 2015. 
MARCONI, Marina A.; LAKATOS, Eva Maria. Técnicas de pesquisa. 4. ed. São Paulo: Atlas, 1999.

MEDEIROS, Beatriz Luce; MEDEIROS, Isabel Letícia Pedroso de (Org.). Gestão escolar democrática: concepções e vivências. Porto Alegre: Editora da UFRGS, 2006.

MIRANDA, Nonato Assis de; VERASZTO, Estéfano V. A formação inicial do gestor educacional na região do grande ABC Paulista. Revista @mbienteeducação, v. 7, n1. 2014, p. 166-174.

MIRANDA, Nonato Assis de; APARíCIO, Ana Silvia Moço; ANDRADE, Maria de Fátima Ramos de. A Educação Infantil nas Cidades do Consórcio do Grande ABC e o Plano Nacional de Educação: avanços e retrocessos. EccoS - Revista Científica, São Paulo, n. 37, maio/ago. 2015, p. 59-75,

PALMEN, Sueli Helena de Camargo. O trabalho do gestor na educação infantil: concepções, cenários e práticas. Tese (doutorado em educação) apresentado à Faculdade de Educação da Unicamp. Campinas-SP, 2014.

TOMÉ, Marta Fresneda. A especificidade das Instituições de Educação Infantil: algumas contribuições para a pesquisa em Gestão Escolar. Anais do XII Encontro Estadual da ANPAE-SP - textos completos. Campinas, SP: UNICAMP/FE, 2012. p.1036-1047.

TREZZI, Clóvis; ROSA, Gabriela Rodrigues Almeida da. Os ambientes educativos na creche e sua influência desenvolvimento da criança. Revista @mbienteeducação. São Paulo: Universidade Cidade de São Paulo, v. 13, n. 1, Jan/Abr, 2020, p. 176-190.

\section{SOBRE OS AUTORES:}

NONATO ASSIS DE MIRANDA. Doutor em Educação pela Universidade Estadual de Campinas, Unicamp. Coordenador do Programa de Pós-Graduação em Educação da Universidade Municipal de São Caetano do Sul - USCS. Professor e Universidade Paulista (UNIP).

FERNANDA GOMES DE OLIVEIRA. Licencianda em Pedagogia, bolsista de Iniciação Científica do CNPq, na Universidade Municipal de São Caetano do Sul (UCS).

ANDRÉ DOS ANJOS CANGUEIRO SILVA. Mestrando em Educação pela Universidade Municipal de São Caetano do Sul (USCS), Professor da Universidade Paulista (UNIP). 


\section{REVISTA @imbienteeducação}

MIRANDA, NA; OLIVEIRA, FG; SILVA, AAC; OLIVEIRA, JMNM; COSTA, LS. Desafios da gestão escolar na educação infantil: a concepção das diretoras. Revista @mbienteeducação. São Paulo: Universidade Cidade de São Paulo, v. 13, n. 2, p. 117-135 Mai/Ago 2020.

JUNCELIA MARQUES NEVES MARTINS DE OLIVEIRA. Mestranda em Educação pela Universidade Municipal de São Caetano do Sul; Diretora de Escola do Município de Santo André (SP).

LILIANE SILVA COSTA. Mestranda em Educação pela Universidade Municipal de São Caetano do Sul; Diretora de Escola do Município de Santo André (SP).

RECEBIDO: 09/04/2020.

APROVADO: 27/04/2020. 